\title{
Mass Spectrometry of Phenylthiohydantoin (PTH)
}

\section{Amino Acids}

\author{
B E N G T W. MELVAS
}

Department of Analytical Chemistry, University of Gothenburg, S.402 20 Göteborg 5, Sweden

\begin{abstract}
The mass spectra have been recorded for five PTH amino acids (alanine, proline, valine, leucine, and isoleucine with an LKB 9000 gas chromatograph-mass spectrometer. An almost complete analysis of the fragment patterns has been carried out, which serves as a convenient tool for the identification of the different amino acids. The peaks for $m / e=$ molecular weight are very intense. The PTH derivatives of the amino acids can be well separated without decomposition using a 2-3 m SE-30 column at $200^{\circ} \mathrm{C}$.
\end{abstract}

$\mathrm{T}$ here is considerable interest in improving the sequence analysis of amino acids. It is well known that Sanger used fluorodinitrobenzene to label the terminal amino groups in peptides. Hydrolysis of the peptides frees the yellow dinitrophenyl (DNP) amino acid, which is subsequently analyzed. With Edman's method the phenylthiohydantoin (PTH) derivative is formed with the terminal amino acid. This derivative is then freed by partial hydrolysis of the peptide and the procedure, which can be carried out automatically, is then repeated with the next terminal amino acid. Amino acid derivatives are generally identified by paper or thin layer chromatography procedures, which are convenient and relatively rapid. Very small amounts of the DNP derivatives can be detected with an electron capture detector, used in gas chromatography, as has been shown by Landowne. ${ }^{1}$

Pisano, VandenHeuvel and Horning ${ }^{2}$ have separated the PTH and DNP derivatives of thirteen amino acids by gas chromatography. In the present work it is shown that the separation of six aliphatic amino acids can be completed within $5 \mathrm{~min}$. The main purpose of the work was, however, to investigate whether the PTH derivatives of the amino acids from the gas chromatograph could be identified by mass spectrometry, and whether the derivatives were affected by the gas chromatographic procedure. Further work is necessary to determine which of the detecting devices is most sensitive, argon, ${ }^{1}$ electron capture, flame ionization, or mass spectrometry. 


\section{GAS CHROMATOGRAPHY}

The chromatographic analysis was carried out with a Perkin-Elmer 881 gas chromatograph equipped with a flame ionization detector, or with the LKB 9000 gas chromatograph-mass spectrometer. Both gas chromatographs were equipped with SE-30 columns, and helium was used as carrier gas. The separation was less effective with argon or nitrogen. The injector block was kept at $240^{\circ} \mathrm{C}$ and the oven temperature at $200^{\circ} \mathrm{C}$. The diameter of the columns was $3 \mathrm{~mm}$ (1/8 inch) and the column length $2 \mathrm{~m}(\mathrm{PE} 881)$ or $3 \mathrm{~m}$ (LKB 9000). The flow rates were $37 \mathrm{ml} / \mathrm{min}(\mathrm{PE} 881$ ) or $25 \mathrm{ml} / \mathrm{min}$ (LKB 9000). The retention times $(\mathrm{min})$ for the following five PTH amino acids with the LKB 9000 were alanine 2.20 , proline 2.50 , valine 2.75 , leucine 3.50 and isoleucine 3.75. The PTH amino acids were purchased from Mann Research Laboratories Inc., New York.

\section{MASS SPECTROMETRY}

Equipment. The main parts of the LKB 9000 gas chromatograph-mass spectrometer are the GLC column, the molecule separator, which was kept at $200^{\circ} \mathrm{C}$, where most of the helium and a large part of the solvent are removed, the ion source, kept at $250^{\circ} \mathrm{C}$, and the analyzer. The ionization energy was $70 \mathrm{eV}$ and the internal pressure of the analyzer was $2 \times 10^{-7}$ torr. The total ionization current can also be measured and serves as a detector for the gas chromatograph.

Results. The results are presented in Figs. 1-5. These diagrams are obtained from the primary spectra after subtracting the background. The $m / e$ scale was determined with standards. The peak heights are given in a normalized scale representing the ratios to the highest peak.

Discussion. Previously mass spectrometric analyses of the methyl and ethyl esters of amino acids have been carried out by Biemann ${ }^{3,4}$ and by Stenhagen.5 Andersson ${ }^{6}$ has shown that the "amine fragment" gives the most intense peak due to the cleavage of the carboxyester group.<smiles>[R]OC(=O)C([R])N</smiles>

The molecular weight $(M)$ is obtained by adding the mass of $\mathrm{COOR}^{\prime}\left(\mathrm{R}^{\prime}=\mathrm{CH}_{3}\right.$ or $\mathrm{C}_{2} \mathrm{H}_{5}$ ) to the mass of the amine fragment. The peaks at $m / e=M$ are generally very weak, and can not be used for quantitative analysis. The peaks at $M$ minus COOR' appear in a region where many other fragments are found. As seen from Figs. $1-5$ this is not the case with the PTH derivatives, which all give a large peak for $m / e=M$.

The fragmentation pattern of the PTH derivatives of the amino acids can be described as follows. Between $m / e=M$ and $m / e=192$ peaks appear due to $\mathrm{C}_{n} \mathrm{H}_{m}$ fragments which have been split off. As expected these peaks are very small in the spectra of alanine (Fig. 1) and in particular proline (Fig. 2). The peak at $m / e=192$ most probably arises from the phenylthiohydantoin ion 
<smiles>O=C1CNC(=S)N(c2ccccc2)C1</smiles>

For proline (Fig. 2) this peak is not present; this can be explained by its pyrrolidine carboxylic acid structure. Alanine shows a small peak compared with valine, leucine and isoleucine. The length of the carbon chain is directly proportional to the ease of fragmentation and isoleucine, with the side chain closer to the broken bond, has a greater tendency to fragmentate than leucine.

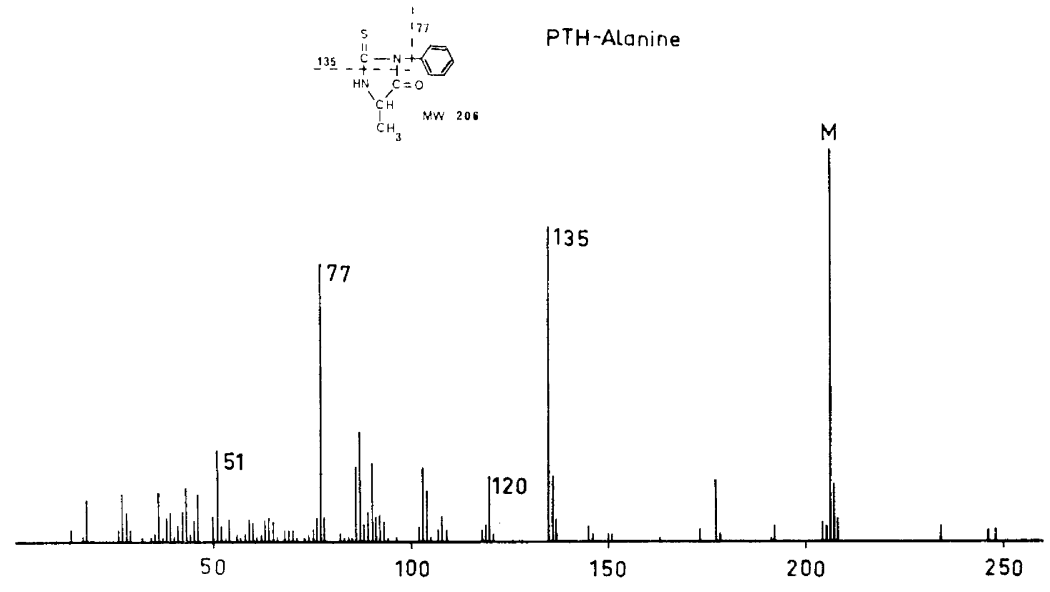

Fig. 1.

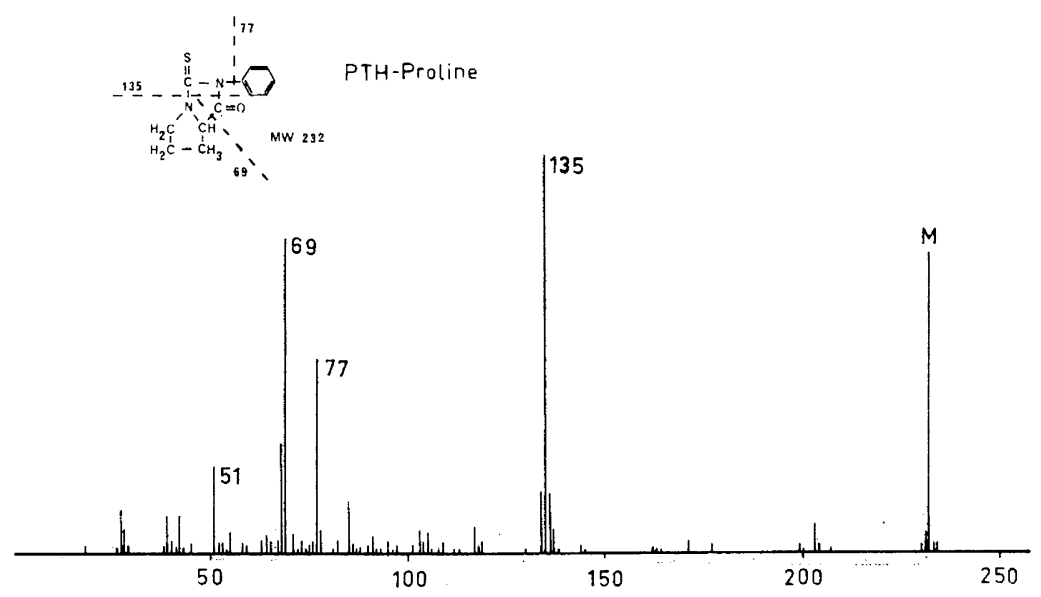

Fig. 2.

Acta Chem. Scand. 23 (1969) No. 5 
The fragment $m / e=177$ is most dominant for alanine (Fig. 1) and could be<smiles>CC1NC(=O)C2C3CCC2C1C3</smiles>

which can be formed by splitting off all the carbon atoms in the amino acid except the carboxyl group. The peak at $m / e=135$, the most intense peak for all the amino acids studied with the exception of alanine, arises from the production of phenylisothiocyanate ion. A peak at $m / e=120$, which

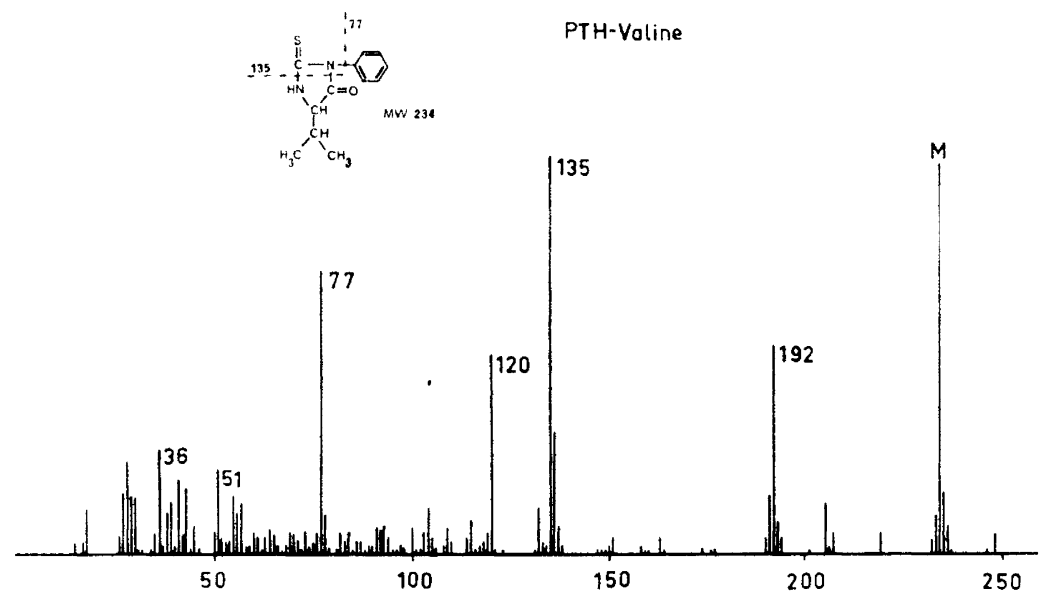

Fig. 3.

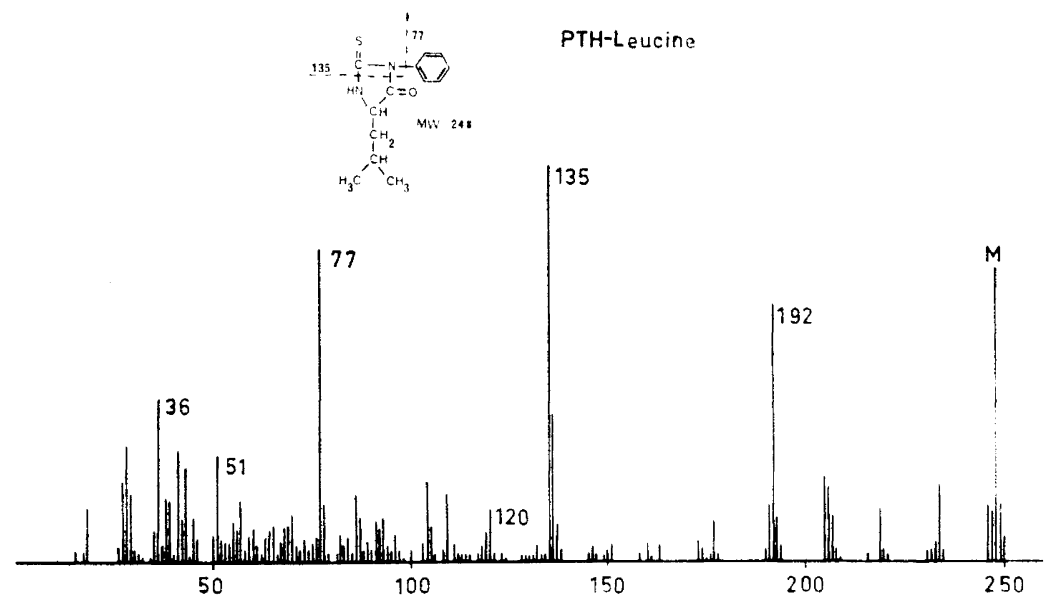

Fig. 4.

Acta Chem. Scand. 23 (1969) No. 5 


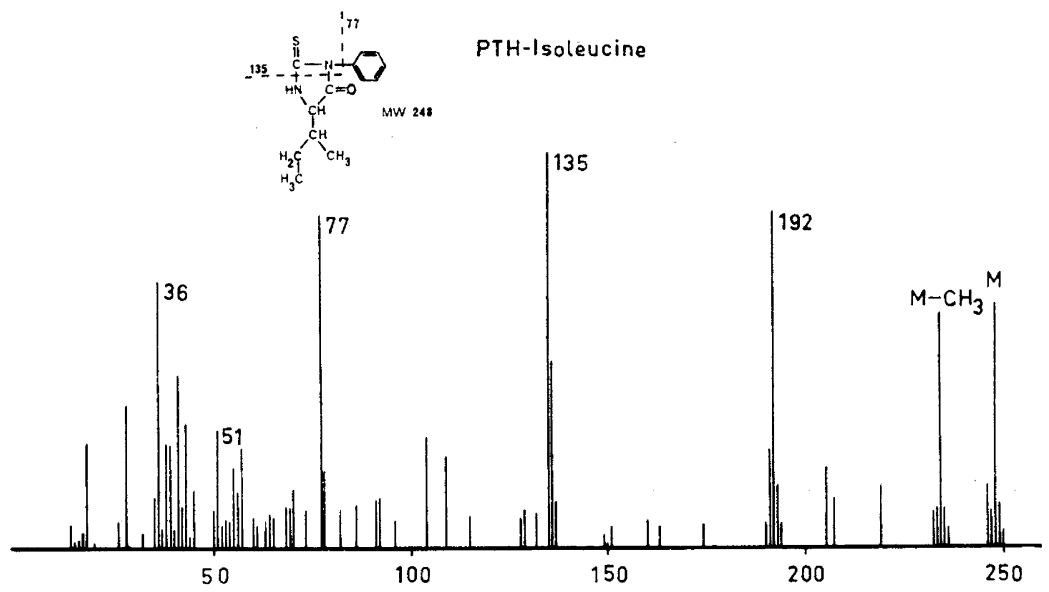

Fig. 5 .

is especially large with valine (Fig. 3) but missing for proline and isoleucine, can be explained by ring cleavage of the phenylthiohydantoin and transfer of a proton

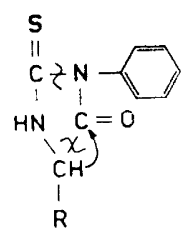

The peak at $m / e=77$ arises from the phenyl ion $\mathrm{C}_{6} \mathrm{H}_{5}{ }^{+}$. Proline (Fig. 2) forms a very intense fragment consisting of pyrroline ion

$$
\left[\begin{array}{c}
\mathrm{N} \\
\mathrm{C}_{\mathrm{H}} \mathrm{C} \\
\mathrm{H} \mathrm{CH} \\
\mathrm{H}_{2} \mathrm{C}-\mathrm{CH}_{2}
\end{array}\right]^{+}
$$

at $m / e=69$. The fragment $\mathrm{C}_{4} \mathrm{H}_{3}{ }^{+}$at $m / e=5 \mathrm{l}$ appears in all the spectra. It is quite common with aromatic compounds and arises from the cleavage of the phenyl group. In general, however, this peak is not so intense as in the present cases. The peak at $m / e=36$ appears in the cases where the PTH derivatives were injected as hydrochlorides (Figs. 3, 4, and 5).

There also appear groups of fragments at $m / e=29,43$, and 57 , which may be $\mathrm{C}_{n} \mathrm{H}_{2 n+1} \mathrm{CO}$, but are most probably $\mathrm{C}_{n} \mathrm{H}_{2 n+1}$. The same is true for $m / e 28,42$, and 56 representing $\mathrm{C}_{n} \mathrm{H}_{2 n}$ and for $m / e=27,41$, and 55 caused by the fragments $\mathrm{C}_{n} \mathrm{H}_{2 n-1}$.

Acta Chem. Scand. 23 (1969) No. 5 
Acknowledgements. The author wishes to thank the head of the department, Professor David Dyrssen, for valuable discussions. The mass spectrograph was operated by civ. ing. Klas Anjou at the Swedish Institute for Food Preservation. The PTH derivatives were obtained from the Department of Biochemistry. Part of our gas chromatographic equipment was purchased with a grant from Wilhelm och Martina Lundgrens Vetenskapsfond.

\section{REFERENCES}

1. Landowne, R. A. and Lipsky, S. R. Nature 194 (1963) 141.

2. Pisano, J. J., VandenHeuvel, W. J. A. and Horning, E. C. Biochem. Biophys. Res. Commun. 7 (1962) 82.

3. Biemann, K., Seibl, J. and Gapp, F. Biochem. Biohys. Res. Commun. 1 (1959) 307.

4. Biemann, K. and Vetter, W. Biochem. Biophys. Res. Commun. 2 (1960) 93.

5. Stenhagen, E. Z. Anal. Chem. 181 (1961) 462.

6. Andersson, C. O. Acta Chem. Scand. 12 (1958) 1353.

Received October 30, 1968. 